Objective This longitudinal study examined changes in maternal weight and Body Mass Index (BMI) in the early pregnancy between a woman's first and second baby.

Methods We studied women more than 18 years old with a singleton pregnancy who delivered their first baby weighing $\geq 500$ grammes in 2009 and who re-attended for antenatal care with a subsequent ongoing pregnancy before January $1^{\text {st }} 2012$. Maternal weight and height were measured accurately before 18 weeks gestation in both pregnancies and BMI was calculated.

Results Of the 3284 primigravidas, the mean weight at the first antenatal visit was $66.4 \mathrm{~kg}$ (SD 12.7). The mean BMI was $24.5 \mathrm{~kg} / \mathrm{m}^{2}$ (SD 4.6), and $11.3 \%(\mathrm{n}=370)$ were obese. Of these 3284 women, $1220(37.1 \%)$ re-attended for antenatal care before 2012 after confirmation of an ongoing pregnancy. Of the 1220 women who re-attended, $788(64.6 \%)$ had gained weight (mean $4.6 \mathrm{~kg}$ SD 3.9), 402(33.0\%) had lost weight (mean $3.0 \mathrm{kgs} \mathrm{SD} 2.9$ ) and 30 (2.4\%) had maintained their weight. As a result, $20.2 \%(\mathrm{n}=247)$ were now in a higher BMI category and $4.8 \%(n=58)$ had become obese; $5.8 \%(n=71)$ were in a lower BMI category and $1.2 \%(n=15)$ were no longer obese. These early pregnancy weight changes were influenced by maternal age, but not by the duration of the interpregnancy interval.

Conclusion As two thirds of women gain weight in the shortterm after delivery of their first baby, we recommend that the advice women get before and during pregnancy needs to be reinforced postpartum.

\section{PP.26 SUSTAINABLE VOLUNTEERING AND ITS EFFECT ON UGANDAN STILLBIRTH RATES}

doi:10.1136/archdischild-2013-303966.306

'K MacLeod, ' 2 L Ackers. 'Mersey Deanery, Liverpool, UK; ${ }^{2}$ University of Liverpool, Liverpool, UK

Background The Ugandan Maternal and Newborn Hub is a THET funded initiative focused on implementing Sustainable Volunteering Projects (SVPs) to improve maternal and newborn health. Annually, there are 2.65 million stillbirths worldwide and almost $90 \%$ occur in low-resource settings. Up to $70 \%$ of stillbirths occur in the intrapartum period; frequently these are associated with suboptimal care.

Methods Through a SVP, from January to June 2012, we undertook a quality improvement project aiming to reduce intrapartum stillbirths at Mbarara Hospital in Uganda. Our quality improvements included regular audit presentations, implementation of a labour ward board and skills and drills training. We classified suboptimal care into types of delay using Thaddeus \& Maine Three Delay Model.

Results In this 6 months period, there were 102 intrapartum stillbirths. Most stillbirths were singleton pregnancies (99\%) with a mean maternal age of 24 years and a mean parity of $2.34 \%$ of women were unbooked. Suboptimal factors contributing to

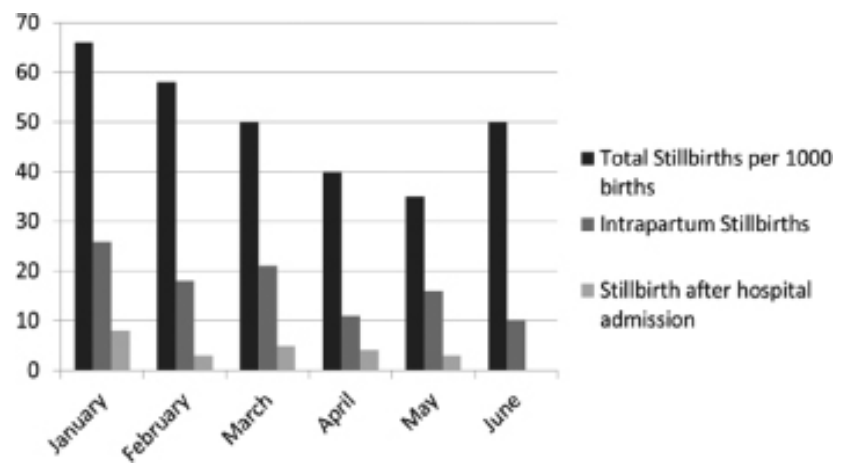

Abstract PP.26 Table Stillbirths Figures Mbarara Hospital 2012 intrapartum stillbirths were identified in $86.4 \%$ of cases, $22 \%$ were related to care whilst admitted. Intrapartum stillbirths occurring after hospital admission reduced after introduction of quality improvement measures: see table.

Discussion Basic and comprehensive emergency obstetric care is an important intervention to reduce intrapartum stillbirths in the developing world. SVPs are an effective way of individualising quality improvement measures and improving outcomes.

\section{PP.27 MICRO-VASCULAR DISEASE AT BOOKING IN T1DM AND ASSOCIATED RISK OF DEVELOPING PRE-ECLAMPSIA}

doi:10.1136/archdischild-2013-303966.307

${ }^{1} \mathrm{~N}$ Patel, ${ }^{2} \mathrm{~A}$ Brackenridge, ${ }^{3} \mathrm{~A}$ Kanji, ${ }^{1} \mathrm{D}$ Pasupathy, ${ }^{4} \mathrm{D}$ Rajasingam. 'Division of Women's Health, Women's Health Academic Centre, King's College London, King's Health Partners, London, UK; 'Department of Diabetes, Guy's and St Thomas' NHS Foundation Trust, London, UK; ${ }^{3}$ School of Medicine, King's College London, London, UK; ${ }^{4}$ Division of Women's Services, Guys and St Thomas' NHS Foundation TRust, London, UK

Background and Aims Micro-vascular disease affects the majority of T1DM patients and is directly related to both duration and glycemic control of diabetes. The aim of this study is to identify the association of micro-vascular disease at booking and subsequent risk of developing pre-eclampsia during pregnancy.

Methods Retrospective cohort study of women with T1DM $(\mathrm{n}=37)$ on continuous subcutaneous insulin infusions booked at Guy's \& St Thomas' Hospital between November 2010 and April 2012. Micro-vascular disease at booking was, defined as nephropathy or/and retinopathy at booking.

Results The prevalence of micro-vascular disease at booking was $54.1 \%(n=20)$. No significant difference were seen in age (33.5 years vs 35.0 years; $p=0.28)$, HbA1c (7.5 vs $6.9 ; p=0.11)$, length of diabetes $(16.0$ years versus 23.0 years; $p=0.14)$ compared to women without micro-vascular disease.

Presence of micro-vascular disease was significantly associated with the pre-eclampsia $(55.0 \%$ vs $17.6 \%$; $\mathrm{p}=0.02$; unadjusted $\mathrm{OR}$ 5.70; CI 1.24-26.26). This association was not explained by maternal age, duration or control of diabetes, parity, BMI and maternal hypertension (adjusted OR 4.92; CI 0.7-32.3).

The rate of LGA and SGA was $51.3 \%$ and $5.4 \%$ respectively. Women with micro-vascular disease had higher rates of SGA $(10.0 \%$ vs $0.0 \%$; $p<0.05)$ and LGA $(65.0 \%$ vs $35.0 \%$; $<<0.05)$.

\section{PP.28 CERVICAL CERCLAGE: ARE ALL TECHNIQUES SUCCESSFUL?}

doi:10.1136/archdischild-2013-303966.308

${ }^{1}$ EA Bonney, ${ }^{2} \mathrm{~A}$ Atkinson, ${ }^{2} \mathrm{R}$ Lancaster, ${ }^{1} \mathrm{JJ}$ Walker, ${ }^{1} \mathrm{NAB}$ Simpson. 'Division of Clinical Sciences, Leeds Institute of Molecular Medicine, University of Leeds, Leeds, UK; ${ }^{2}$ School of Medicine, University of Leeds, Leeds, UK

Objective Preterm birth is a global public health issue. In women considered high risk, insertion of a cervical cerclage has been shown to reduce this risk. We present findings from a retrospective cohort evaluating the success of different cerclage procedures (Shirodkar, McDonald and Transabdominal) in a tertiary level obstetric unit.

Study design Retrospective data was collected for 200 women who underwent a cerclage procedure at Leeds Teaching Hospitals NHS Trust between August 2000 and October 2010. Exclusion criteria for the study included multiple pregnancy, insertion of more than one cerclage in a single pregnancy, or an incomplete data record. Success was measured by delivery of a live baby $\geq 34$ weeks. Mean gestational age (MGA) for each group was also calculated. Statistical analysis was performed using Fisher's exact test. 